\title{
Methotrexate-Associated Lymphoproliferative Disorder of the Stomach Observed by Magnifying Narrow-Band Imaging Endoscopy
}

\author{
Keisuke Kawasaki ${ }^{1}$, Makoto Eizuka $^{2}$, Shotaro Nakamura ${ }^{1}$, Tamotsu Sugai ${ }^{2}$, Takayuki Matsumoto ${ }^{1}$
}

1) Division of Gastroenterology, Department of Internal Medicine, Iwate Medical University, Morioka;2) Department of Diagnostic Pathology, Iwate Medical University, Morioka, Japan
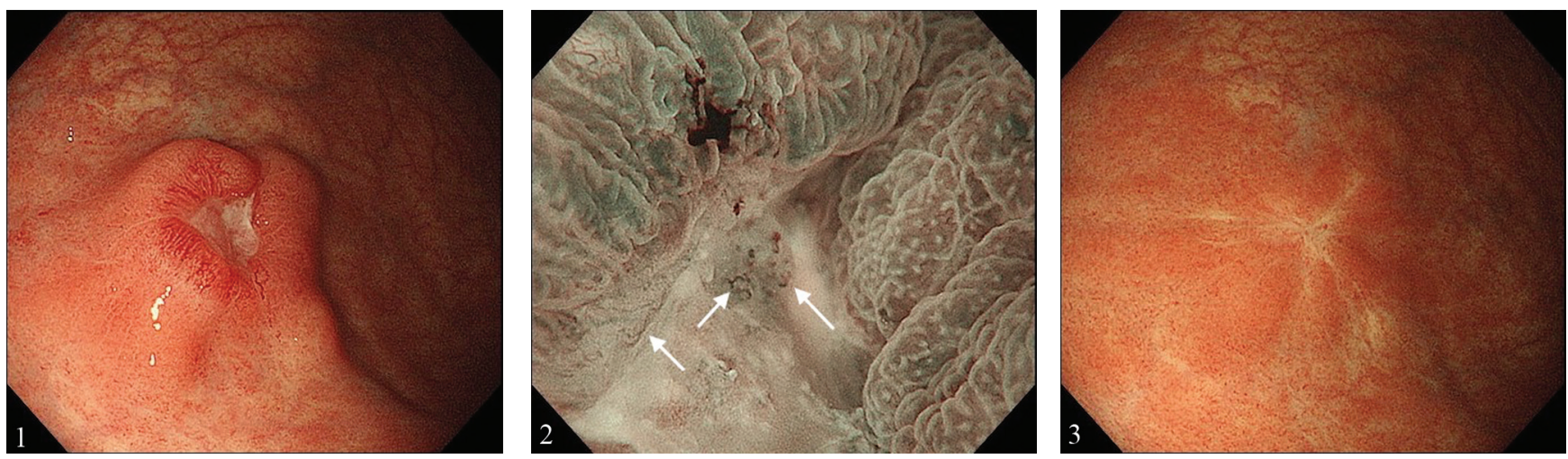

A 70-year-old man with a 3-year history of rheumatoid arthritis (RA) underwent esophagogastroduodenoscopy (EGD) for gastric cancer screening, which showed a submucosal tumor-like lesion with a central ulcer in the middle third of the stomach (Fig. 1). Magnifying narrow-band imaging (M-NBI) endoscopy revealed thin and tortuous vessels in the oral edge of the lesion (Fig. 2, arrows). Histologic examination of biopsy specimens from the oral edge of the lesion revealed diffuse proliferation of the large-sized atypical lymphoid cells with CD10+, CD20+, CD3+, CD5+, BCL2- and cyclinD1immunophenotype, and with the Ki-67 labelling index of $91.3 \%$. In situ hybridization for Epstein-Barr virus demonstrated no positivity in atypical lymphoid cells. He was positive for Helicobacter pylori by serology. 18F-fluorodeoxyglucose (FDG) positron emission tomography showed increased FDG avidity only in the stomach. Other investigations including capsule endoscopy, colonoscopy and bone marrow biopsy revealed no abnormality. Because he had been treated with methotrexate (MTX) for RA, we diagnosed this case as MTX-associated lymphoproliferative disorder (MTX-LPD) showing features of diffuse large B-cell lymphoma. We discontinued MTX without any specific treatment for MTX-LPD. Follow-up EGD two months later showed disappearance and scarring of the tumor, and atypical lymphoid cell proliferation was absent in biopsy specimens (Fig. 3).

Methotrexate unrelated gastric malignant lymphoma has been shown to manifest various endoscopic features; M-NBI endoscopic findings are destruction of the gastric pits or microvascular abnormalities [1-4]. On the other hand, gastric MTX-LPD is extremely rare. Furthermore, M-NBI endoscopic findings of gastric MTX-LPD have not been reported to date. In our case, the thin and tortuous vessel patterns of gastric MTX-LPD under M-NBI endoscopy were less irregular in comparison with MTX-unrelated gastric malignant lymphoma. Our case suggests that gastric MTX-LPD may have M-NBI endoscopic features distinct from those of MTX-unrelated gastric malignant lymphoma.

Corresponding author:Keisuke Kawasaki, kkeisuke@iwate-med.ac.jp

Conflicts of interest: None to declare.

\section{REFERENCES}

1. Nakamura S, Matsumoto T, Iida M, Yao T, Tsuneyoshi M. Primary gastrointestinal lymphoma in Japan: a clinicopathologic analysis of 455 patients with special reference to its time trends. Cancer 2003;97:24622473. doi:10.1002/cncr.11415

2. Taal BG, Boot H, van Heerde P, de Jong D, Hart AA, Burgers JM. Primary non-Hodgkin lymphoma of the stomach: endoscopic pattern and prognosis in low versus high grade malignancy in relation to the MALT concept. Gut 1996;39:556-561. doi:10.1136/gut.39.4.556

3. Fischbach W, Dragosics B, Kolve-Goebeler ME, et al. Primary gastric B-cell lymphoma: results of a prospective multicenter study. The German-Austrian Gastrointestinal Lymphoma Study Group. Gastroenterology 2000;119:1191-1202. doi:10.1053/gast.2000.19579

4. Isomoto $\mathrm{H}$, Matsushima $\mathrm{K}$, Hayashi $\mathrm{T}$, et al. Endocytoscopic findings of lymphomas of the stomach. BMC Gastroenterol 2013;13:174. doi:10.1186/1471-230X-13-174 